\title{
USO DE ADITIVOS NA BIODEGRADAÇÃO DE MADEIRA PELO FUNGO Ceriporiopsis subvermispora: EFEITO NA PEROXIDAÇÃO DE LIPÍDIOS DEPENDENTE DE MANGANÊS-PEROXIDASE
}

\author{
André Aguiar* \\ Departamento de Química, Biotecnologia e Engenharia de Bioprocessos, Universidade Federal de São João Del-Rei, Campus Alto \\ Paraopeba, CP 131, 36420-000 Ouro Branco - MG, Brasil
}

André Ferraz

Departamento de Biotecnologia, Escola de Engenharia de Lorena, Universidade de São Paulo, CP 116, 12602-810 Lorena - SP, Brasil

Recebido em 12/7/11; aceito em 6/12/11; publicado na web em 31/1/12

\begin{abstract}
USE OF ADDITIVES IN THE WOOD BIODEGRADATION BY THE FUNGUS Ceriporiopsis subvermispora: EFFECT IN THE MANGANESE PEROXIDASE-DEPENDENT LIPID PEROXIDATION. Ceriporiopsis subvermispora is a selective fungus in the wood delignification and the most promising in biopulping. Through the lipid peroxidation initiated by manganese peroxidase $(\mathrm{MnP})$, free radicals can be generated, which can act in the degradation of lignin nonphenolic structures. This work evaluated the prooxidant activity (based in lipid peroxidation) of enzymatic extracts from wood biodegradation by this fungus in cultures containing exogenous calcium, oxalic acid or soybean oil. It was observed that $\mathrm{MnP}$ significant activity is required to promote lipid peroxidation and wood delignification. Positive correlation between prooxidant activity x MnP was observed up to $300 \mathrm{IU} \mathrm{kg}^{-1}$ of wood.
\end{abstract}

Keywords: wood biodegradation; manganese peroxidase; lipid peroxidation.

\section{INTRODUÇÃO}

Ceriporiopsis subvermispora é uma espécie de fungo causador de podridão branca seletivo na deslignificação de madeira, sendo o mais estudado na tecnologia de biopolpação. ${ }^{1}$ Este processo consiste em um pré-tratamento biológico de cavacos de madeira, seguido de processos convencionais de polpação (mecânica ou química). Para degradar os componentes da parede celular vegetal, esse fungo secreta uma série de enzimas hidrolíticas e oxidativas, ${ }^{2-4}$ além de compostos de baixa massa molar, os quais são importantes em atuar nos estágios iniciais de colonização da madeira. ${ }^{5}$

Esse fungo não produz lignina-peroxidase (LiP), enzima que possui potencial de oxidação suficiente para abstrair elétrons de estruturas não fenólicas da lignina, as quais apresentam maiores abundância e recalcitrância. ${ }^{6}$ A manganês-peroxidase $(\mathrm{MnP})$ é a principal enzima oxidativa produzida por esse fungo durante a biodegradação de madeira. ${ }^{2-4}$ Essa enzima oxida fenóis, mas seu principal substrato é o íon $\mathrm{Mn}^{2+}$. $\mathrm{O} \mathrm{Mn}{ }^{3+}$ gerado pela $\mathrm{MnP}$ necessita de quelantes para estabilizá-lo, como o ácido oxálico. O complexo oxalato- $\mathrm{Mn}^{3+}$ formado oxida apenas porções fenólicas da lignina, assim como a enzima lacase, ${ }^{6}$ que é também produzida por $C$. subvermispora. ${ }^{2-4}$ Todavia, a despolimerização de lignina in natura tem sido observada em cultivos desse fungo sobre madeira ${ }^{1}$ e também em culturas submersas contendo compostos modelo de lignina não fenólicos, ${ }^{7}$ sendo atribuída aos radicais livres gerados a partir da peroxidação de lipídios ou de ácidos graxos insaturados, iniciada por $\mathrm{Mn}^{3+}$ oriundo da ação da MnP. A Figura 1 mostra um fragmento não fenólico de lignina com ligação $\beta-\mathrm{O}-4$ sendo clivada por um radical peroxila $\left(\mathrm{RO}_{2}{ }^{\circ}\right)$.

Além de estruturas não fenólicas da lignina, radicais livres gerados em sistemas contendo $\mathrm{MnP}, \mathrm{Mn}^{2+}$, um ácido dicarboxílico, $\mathrm{H}_{2} \mathrm{O}_{2}$ e um ácido graxo (como o ácido linoleico), podem atuar na degradação de compostos recalcitrantes ${ }^{8}$ e no biobranqueamento de polpas celulósicas. ${ }^{9}$ Uma revisão apontando os principais mecanismos de biodegradação de madeira e suas aplicações tecnológicas correlatas foi publicado recentemente nesse mesmo periódico. ${ }^{6}$

\footnotetext{
*e-mail: andrepiranga@yahoo.com.br
}

Anteriormente, foi desenvolvido um método analítico que avalia a peroxidação de lipídios por caldos de culturas fúngicas baseado no consumo de $\mathrm{O}_{2}$ dissolvido, como forma de estimar suas atividades pró-oxidantes. ${ }^{10}$ Ao ser atacado por um agente oxidante, a molécula do ácido linoleico consome $\mathrm{O}_{2}$, sendo convertida a radical peroxila. ${ }^{6}$

Para entender o que ocorre durante a biodegradação de lignina em madeira por $C$. subvermispora é preciso avaliar a atividade pró-oxidante de suas culturas. Atividades pró-oxidantes de culturas submersas e de caldos enzimáticos provenientes da biodegradação de Eucalyptus grandis (madeira dura) por esse mesmo fungo foram<smiles>[R20][Y]([R20])([H])C(O)c1ccc(OC)c(OC)c1</smiles><smiles>COc1ccc(C(O)C(CO)Oc2ccc(C)cc2OC)cc1OC</smiles><smiles>COc1cc(C)ccc1Oc1cc(C(=O)CCO)ccc1OC</smiles>

Figura 1. Degradação de um fragmento de lignina (não fenólico) por radical peroxila $\left(\mathrm{RO}_{2}{ }^{\circ}\right)$ gerado pelo sistema $\mathrm{MnP} / \mathrm{Mn}^{2+} / a$ cido linoleico/ $\mathrm{H}_{2} \mathrm{O}_{2}$. A instabilidade do radical intermediário resulta na formação de uma $\alpha$-carbonila paralela ao rompimento da ligação $\beta-O-4$ 
avaliadas recentemente. ${ }^{11}$ Para o presente trabalho, foram estudadas 4 condições de cultivo de $C$. subvermispora sobre uma madeira macia, Pinus taeda, quanto à atividade pró-oxidante. Um desses cultivos foi realizado sem nenhum aditivo (controle) e os outros três contendo 1,4 $\mathrm{g}_{\text {de }} \mathrm{Ca}^{2+} \mathrm{kg}^{-1}, 1,66 \mathrm{~g}$ de ácido oxálico $\mathrm{kg}^{-1}$ ou 10,4 g de óleo de soja $\mathrm{kg}^{-1}$ de madeira. Esses aditivos já haviam sido estudados anteriormente: os dois primeiros tiveram o intuito de avaliar a importância de ácido oxálico na biodegradação de madeira, seja por meio de sua indisponibilização (formação de oxalato de cálcio insolúvel), ou pela sua adição exógena, o que deveria estimular o ciclo catalítico da $\mathrm{MnP},{ }^{12}$ pois essa enzima depende de quelantes de $\mathrm{Mn}^{3+}$; o terceiro aditivo (óleo de soja) teve o intuito de estimular as reações de peroxidação de lipídios. ${ }^{13} \mathrm{O}$ primeiro aditivo com essa carga havia inibido o processo biodegradativo como um todo; o segundo não afetou a produção de metabólitos, muito menos a degradação dos componentes da madeira, enquanto o terceiro estimulou reações de peroxidação, porém não causou maior deslignificação. Cultivos com esses três aditivos foram repetidos com o intuito de buscar correlações entre a secreção de enzimas e ácido oxálico, produtos da peroxidação de lipídios in vivo (TBARS -thiobarbituric acid reactive substances), atividade redutora de $\mathrm{Fe}^{3+}$, bem como as alterações na composição química da madeira biotratada frente à atividade pró-oxidante dessas culturas.

\section{PARTE EXPERIMENTAL}

\section{Fungo, preparo do inóculo e biodegradação da madeira}

O fungo empregado foi o basidiomiceto Ceriporiopsis subvermispora L14807-SS3, mantido em placas de Petri contendo $2 \%$ de extrato de malte, $0,2 \%$ de extrato de levedura e $2 \%$ de ágar, cultivado a $27 \pm 2{ }^{\circ} \mathrm{C}$. O fungo foi repicado em meio líquido contendo $2,4 \%$ de extrato de batata/dextrose e $0,7 \%$ de extrato de levedura. Após 13 dias de incubação estática a $27 \pm 2{ }^{\circ} \mathrm{C}$, o micélio crescido foi filtrado, lavado e macerado em água esterilizada para a obtenção do inóculo.

A madeira utilizada foi Pinus taeda com cerca de 28 anos, obtida junto ao Parque Estadual de Campos do Jordão - SP. Os cavacos de madeira $(2,5 \times 1,8 \times 0,2 \mathrm{~cm})$ foram mantidos em água por $15 \mathrm{~h} \mathrm{e}$, depois, o excesso foi drenado. Foram adicionados três aditivos em distintos cultivos: $1,4 \mathrm{~g}$ de $\mathrm{Ca}^{2+} \mathrm{kg}^{-1}, 1,66 \mathrm{~g}$ de ácido oxálico $\mathrm{kg}^{-1}$ ou 10,4 g de óleo de soja kg-1 de madeira em biorreatores de $20 \mathrm{~L}$, contendo cerca de $2 \mathrm{~kg}$ de cavacos (base seca). A esterilização foi realizada a $121{ }^{\circ} \mathrm{C}$ por $15 \mathrm{~min}$. Os biorreatores foram inoculados com a suspensão de micélio (100 mg de micélio $\mathrm{kg}^{-1}$ de madeira) e mantidos por 2 semanas a $27 \pm 2{ }^{\circ} \mathrm{C}$. Como controle, foi realizado um cultivo na ausência de aditivos.

\section{Extração e determinação de enzimas}

A extração das enzimas foi feita com tampão acetato de sódio $50 \mathrm{mmol} \mathrm{L}^{-1}$ (pH 5,5), adicionado de $0,01 \%$ (m/v) de Tween $60 .{ }^{2}$ Aproximadamente $50 \mathrm{~g}$ de cavacos biotratados (em triplicata) foram extraídos com $200 \mathrm{~mL}$ de tampão a $120 \mathrm{rpm}$ durante $5 \mathrm{~h}$ a $12 \pm 1{ }^{\circ} \mathrm{C}$. Os caldos enzimáticos foram centrifugados $(4500 \mathrm{rpm}$, $15^{\circ} \mathrm{C}, 15 \mathrm{~min}$ ) e fez-se a determinação das atividades de $\mathrm{MnP}, \mathrm{LiP}^{2}$ lacase,${ }^{14}$ endoglicanase ${ }^{15}$ e xilanases. ${ }^{16}$ As atividades enzimáticas foram expressas em Unidades Internacionais (UI) $\mathrm{kg}^{-1}$ de madeira inicialmente contida nos cultivos.

\section{Determinação de atividade pró-oxidante in vitro dos caldos enzimáticos}

A atividade pró-oxidante foi determinada a partir do consumo de $\mathrm{O}_{2}$, utilizando como substrato o ácido linoleico. Foi utilizado um oxímetro Hansatech previamente calibrado com água saturada em $\mathrm{O}_{2}$ e também livre de $\mathrm{O}_{2}$. Primeiramente foram colocados na cela do oxímetro $870 \mu \mathrm{L}$ de tampão succinato de sódio $50 \mathrm{mmol} \mathrm{L}^{-1}(\mathrm{pH}$ 4,5), $34 \mu \mathrm{L}$ de ácido oxálico $50 \mathrm{mmol} \mathrm{L}^{-1}(\mathrm{pH} 4,5)$ e $216 \mu \mathrm{L}$ de água destilada. $\mathrm{O} \mathrm{pH}$ escolhido para esses ensaios foi 4,5 , pois esse é o valor ótimo para se medir atividade pró-oxidante da $\mathrm{MnP} .{ }^{10}$ Iniciou-se a agitação magnética da solução na cela até a saturação de $\mathrm{O}_{2}$ a $27^{\circ} \mathrm{C}$. Em seguida, foram adicionados $500 \mu \mathrm{L}$ de caldo enzimático, $40 \mu \mathrm{L}$ de $\mathrm{MnSO}_{4} 5 \mathrm{mmol} \mathrm{L}^{-1}$ e $40 \mu \mathrm{L}$ de emulsão de ácido linoleico $0,2 \%(\mathrm{~m} / \mathrm{v})$ em Tween $601 \%(\mathrm{~m} / \mathrm{v})$. A cela foi lacrada com o êmbolo superior e através de um tubo capilar injetou-se $4 \mu \mathrm{L}$ de $\mathrm{H}_{2} \mathrm{O}_{2} 20$ mmol L ${ }^{-1}$. A taxa máxima de consumo de oxigênio foi determinada por leituras contínuas do eletrodo de oxigênio e expressas em UI kg-1 de madeira. Como controle, fez-se a mesma reação na ausência da emulsão de ácido linoleico em Tween 60.

Para a determinação de TBARS formados a partir da peroxidação do ácido linoleico in vitro foram misturados $1,07 \mathrm{~mL}$ de tampão succinato de sódio $50 \mathrm{mmol} \mathrm{L}^{-1}(\mathrm{pH} 4,5)$ e $56 \mu \mathrm{L}$ de ácido oxálico $50 \mathrm{mmol} \mathrm{L}^{-1}(\mathrm{pH} 4,5)$ por $5 \mathrm{~min}$, a $120 \mathrm{rpm}$ e a $27^{\circ} \mathrm{C}$ no escuro para oxigenação do meio reacional. Em seguida, foram adicionados $50 \mu \mathrm{L}$ de $\mathrm{MnSO}_{4} 50 \mathrm{mmol} \mathrm{L}^{-1}, 500 \mu \mathrm{L}$ de emulsão de ácido linoleico $0,2 \%$ $(\mathrm{m} / \mathrm{v})$ em Tween 60 1\% (m/v) e $1 \mathrm{~mL}$ de caldo enzimático. A reação foi iniciada pela adição de $125 \mu \mathrm{L}$ de $\mathrm{H}_{2} \mathrm{O}_{2} 2 \mathrm{mmol} \mathrm{L}^{-1}$. Os frascos foram vedados e a reação foi mantida sob agitação a $120 \mathrm{rpm}$ a $27^{\circ} \mathrm{C}$. Após $1 \mathrm{~h}, 1 \mathrm{~mL}$ da mistura reacional reagiu com $3 \mathrm{~mL}$ de solução $0,335 \%$ $(\mathrm{m} / \mathrm{v})$ de ácido tiobarbitúrico e $10 \%(\mathrm{~m} / \mathrm{v})$ de ácido tricloroacético em tubos de ensaios com vedação. Após ficarem 15 min em banho em ebulição, o conteúdo de cada tubo foi esfriado, centrifugado e, em seguida, fez-se a leitura do sobrenadante em $532 \mathrm{~nm}\left(\varepsilon=1,56 \times 10^{5}\right.$ $\left.\mathrm{mol}^{-1} \mathrm{~L} \mathrm{~cm}^{-1}\right) .{ }^{17}$ Como controle, fez-se a mesma reação na ausência da emulsão de ácido linoleico em Tween 60. Esses ensaios foram realizados em triplicata.

\section{Determinação de TBARS produzidos durante a biodegradação de madeira}

A determinação de TBARS produzidos in vivo foi realizada em duplicata e de acordo com Aguiar e Ferraz. ${ }^{3}$

\section{Perda de componentes químicos}

Os cavacos de madeira foram moídos em um moinho de facas até passarem por uma malha com perfurações de $0,5 \mathrm{~mm}$. Lignina Klason solúvel mais insolúvel foi determinada em amostras pré-extraídas com etanol 95\% (v/v) e posteriormente hidrolisadas em $\mathrm{H}_{2} \mathrm{SO}_{4} 72 \%(\mathrm{~m} / \mathrm{m})$ em triplicata. Açúcares solúveis presentes nos hidrolisados foram quantificados por CLAE (cromatografia líquida de alta eficiência) usando uma coluna HPX-87H, aquecida a $45^{\circ} \mathrm{C}$ e eluída com $\mathrm{H}_{2} \mathrm{SO}_{4} 5 \mathrm{mmol} \mathrm{L}^{-1}$ com fluxo de $0,6 \mathrm{~mL} \mathrm{~min}^{-1}$. Os teores de celulose (calculado como glicanas totais) e polioses foram calculados considerando-se os monômeros glicose e xilose, respectivamente..$^{18} \mathrm{~A}$ perda de componentes foi calculada a partir da massa inicial subtraída da massa final (após biotratamento).

\section{Determinação da solubilidade de madeira em NaOH $1 \%$}

Cerca de $300 \mathrm{mg}$ de cavacos moídos (base seca) foram tratados com $15 \mathrm{~mL}$ de $\mathrm{NaOH} 1 \%(\mathrm{~m} / \mathrm{v})$ por $1 \mathrm{~h}$ em banho-maria a $100{ }^{\circ} \mathrm{C}$, em tubos com vedação. Os resíduos foram filtrados a vácuo em filtro de vidro sinterizado $\mathrm{N}^{\circ} 3$, lavados com $50 \mathrm{~mL}$ de $\mathrm{NaOH} 1 \%(\mathrm{~m} / \mathrm{v})$ e, posteriormente, com $100 \mathrm{~mL}$ de água destilada. Os resíduos retidos no filtro foram deixados em estufa a $60{ }^{\circ} \mathrm{C}$ e posteriormente a $105^{\circ} \mathrm{C}$ 
até atingirem massa constante. A determinação da solubilidade em $\mathrm{NaOH}$ foi realizada em triplicata.

\section{Extração e determinação de ácido oxálico}

Os cavacos de madeira foram extraídos com água $\mathrm{pH} 7, \mathrm{HCl} \mathrm{0,1}$ mol L-1 e NaOH 0,1 mol L-1 para determinação de ácido oxálico livre, insolúvel e esterificado, respectivamente, por CLAE. ${ }^{3}$

\section{Atividade redutora de $\mathrm{Fe}^{3+}$}

A atividade redutora de $\mathrm{Fe}^{3+}$ foi avaliada ao se reagir $375 \mu \mathrm{L}$ de extrato aquoso (o mesmo extrato utilizado para determinar ácido oxálico livre) com $25 \mu \mathrm{L}$ de $\mathrm{FeCl}_{3} \cdot 6 \mathrm{H}_{2} \mathrm{O} 8 \mathrm{mmol} \mathrm{L}^{-1}$, preparado recentemente na presença de $330 \mu \mathrm{L}$ de tampão acetato de sódio 50 mmol L-1 $(\mathrm{pH} 4,5)$. Após $30 \mathrm{~min}$, foram adicionados $70 \mu \mathrm{L}$ de $\mathrm{NaF}$ $1 \%(\mathrm{~m} / \mathrm{v})$ para paralisar a reação e $200 \mu \mathrm{L}$ de ferrozina $1 \%(\mathrm{~m} / \mathrm{v})$ para reagir com os íons $\mathrm{Fe}^{2+}$ formados. As reações foram realizadas em duplicata. Para o branco, os agentes complexantes e os extratos aquosos foram excluídos. Um ensaio que serviu como um controle foi realizado contendo $\mathrm{FeCl}_{3} \cdot 6 \mathrm{H}_{2} \mathrm{O}$ e ferrozina.

\section{RESULTADOS E DISCUSSÃO}

\section{Metabólitos extracelulares e degradação dos componentes da madeira}

Ao completar 2 semanas de fermentação, observou-se que o cultivo adicionado de óleo de soja foi o que apresentou mais micélio fúngico, seguido dos cultivos com ácido oxálico e sem aditivo. Para o cultivo adicionado de cálcio, não foi possível detectar micélio na superfície dos cavacos. Esses aspectos de colonização foram semelhantes àqueles observados em estudos anteriores. ${ }^{12,13}$

Assim como em outros substratos lignocelulósicos, as atividades xilanolíticas predominaram, enquanto lacases apresentaram valores muito baixos em relação às outras enzimas. Atividades de endoglicanase foram máximas no cultivo com óleo de soja, enquanto a produção de $\mathrm{MnP}$ foi menor apenas no cultivo com cálcio. LiP não foi detectada em nenhum cultivo (Tabela 1).
Para esse grupo de experimentos, as atividade de MnP foram avaliadas da forma tradicional, com ácido láctico $15 \mathrm{mmol} \mathrm{L}^{-1}$ como quelante de $\mathrm{Mn}^{3+}$, e também com ácido oxálico $1 \mathrm{mmol} \mathrm{L}^{-1}$, concentração fisiológica desse quelante em culturas submersas de $C$. subvermispora $1{ }^{19}$ No primeiro caso, os níveis de MnP foram similares entre os cultivos, com exceção da menor atividade observada no cultivo adicionado de cálcio. Ao utilizar ácido oxálico como quelante nos ensaios, observou-se que os níveis de atividade apresentaram um leve acréscimo, principalmente no cultivo com ácido oxálico exógeno, enquanto no cultivo com cálcio a atividade de $\mathrm{MnP}$ foi ainda menor (Tabela 1). Isso pode ser explicado pela provável precipitação do ácido oxálico por cálcio durante os ensaios.

Com relação à degradação dos principais constituintes da madeira, menor perda de lignina foi observada no cultivo com cálcio (Tabela 1), condição em que houve diminuição do crescimento fúngico e também menor atividade de MnP. Os outros cultivos apresentaram perdas de lignina semelhantes entre si. As perdas de celulose foram bem baixas e similares entre as condições de cultivo, enquanto as perdas de polioses foram maiores nos cultivos suplementados com ácido oxálico ou óleo de soja e menores no cultivo com cálcio (Tabela 1). As perdas de componentes observadas nestes cultivos foram similares aos trabalhos anteriores, ${ }^{12,13}$ corroborando que esse fungo é mais seletivo na degradação de lignina nos estágios iniciais de colonização de madeira. ${ }^{1,3}$

Foram observados maiores índices de solubilidade em $\mathrm{NaOH}$ $1 \%$ (forma de se avaliar o grau de decomposição da madeira) para os cavacos de madeira provenientes do cultivo com ácido oxálico e, principalmente, do cultivo com óleo de soja. Para os cultivos com cálcio ou sem aditivo, não foram observadas diferenças significativas em relação aos cavacos não biotratados (Tabela 1).

Quanto aos produtos da peroxidação de lipídios, para o cultivo adicionado de cálcio o teor de TBARS extraído foi similar ao controle (não biotratado), enquanto para os cultivos sem aditivo ou contendo ácido oxálico exógeno foi maior e no cultivo com óleo de soja foi máximo (Tabela 1). Apesar disso, as perdas de lignina foram similares entre os cultivos com óleo ou ácido oxálico e sem aditivo, corroborando que a maior ocorrência de reações de peroxidação de lipídios in vivo não proporciona maior deslignificação de madeira. ${ }^{13}$

A atividade redutora de $\mathrm{Fe}^{3+}$ foi também avaliada nos cultivos,

Tabela 1. Enzimas, perdas de componentes químicos, solubilidade em $\mathrm{NaOH}$, TBARS e atividade redutora de $\mathrm{Fe}^{3+}\left(\mu \mathrm{mol} \mathrm{L}^{-1}\right.$ de $\mathrm{Fe}^{2+}$ gerados após 30 min) analisados nos cultivos de C. subvermispora sobre $P$. taeda

\begin{tabular}{|c|c|c|c|c|c|}
\hline \multirow{2}{*}{ Atividades enzimáticas $\left(\mathrm{UI} \mathrm{kg}^{-1}\right)$} & \multirow{2}{*}{ não biotratado } & \multicolumn{4}{|c|}{ biotratado } \\
\hline & & sem aditivo & $1,4 \mathrm{~g} \mathrm{Ca}^{2+} \mathrm{kg}^{-1}$ & $1,66 \mathrm{~g} \mathrm{AO}^{*} \mathrm{~kg}^{-1}$ & $10,4 \mathrm{~g}$ oleo $\mathrm{kg}^{-1}$ \\
\hline xilanases & - & $622 \pm 131(a)^{* *}$ & $566 \pm 477$ (a) & $894 \pm 300$ (a) & $691 \pm 138$ (a) \\
\hline endoglicanase & - & $37 \pm 3$ (a) & $37 \pm 6(a)$ & $48 \pm 17$ (a) & $75 \pm 10(b)$ \\
\hline lacase & - & $2,4 \pm 1,7$ (a) & $4,5 \pm 1,6$ (a) & $0,5 \pm 0,9$ (a) & 0 \\
\hline MnP (ácido láctico) & - & $174 \pm 6(a)$ & $40 \pm 11$ (b) & $212 \pm 28$ (a) & $206 \pm 25$ (a) \\
\hline MnP (ácido oxálico) & - & $198 \pm 39$ (a) & $14 \pm 11(b)$ & $281 \pm 28$ (c) & $227 \pm 13$ (a) \\
\hline \multicolumn{6}{|c|}{ Perdas de componentes químicos $(\% \mathrm{~m} / \mathrm{m})$} \\
\hline lignina & - & $4,0 \pm 0,6$ (a) & $1,2 \pm 0,6(b)$ & $4,6 \pm 0,9$ (a) & $3,4 \pm 1,0$ (a) \\
\hline celulose & - & $2,1 \pm 0,2(a)$ & $1,6 \pm 0,6$ (a) & $1,2 \pm 0,4$ (a) & $0,9 \pm 0,7$ (a) \\
\hline polioses & - & $1,3 \pm 0,2(a)$ & $0,2 \pm 0,3(b)$ & $2,7 \pm 0,4(c)$ & $3,3 \pm 0,3(\mathrm{c})$ \\
\hline Solubilidade em NAOH $1 \%(\% \mathrm{~m} / \mathrm{m})$ & $8,3 \pm 0,1(a)$ & $8,6 \pm 0,3$ (a) & $8,6 \pm 0,1$ (a) & $9,8 \pm 0,4$ (b) & $13,0 \pm 0,3(\mathrm{c})$ \\
\hline TBARS $\left(\mu \mathrm{g} \mathrm{kg}^{-1}\right)$ & $41 \pm 1$ & $73 \pm 4$ & $39 \pm 3$ & $69 \pm 2$ & $92 \pm 12$ \\
\hline Atividade redutora de $\mathrm{Fe}^{3+}$ & $13,8 \pm 0,3$ & $2,1 \pm 0,3$ & $0,5 \pm 0,1$ & $3,0 \pm 0,1$ & $2,2 \pm 0,1$ \\
\hline
\end{tabular}

*AO - ácido oxálico. **Em cada coluna, letras iguais indicam que os valores não diferem com $95 \%$ de confiança, letras diferentes indicam valores significativamente diferentes (teste de Dunnet). 
pois pode promover a peroxidação de lipídios. ${ }^{20} \mathrm{~A}$ atividade redutora foi superior para o extrato de madeira não biotratada, conforme já observado anteriormente. ${ }^{3}$ Essa maior atividade redutora para o controle pode ser atribuída aos extrativos fenólicos presentes na madeira, os quais são rapidamente consumidos pelo fungo nos estágios iniciais de colonização. ${ }^{3}$ Para os extratos de madeira biodegradada, os valores foram similares e inferiores ao controle. Para o cultivo com cálcio, a atividade redutora foi mínima (Tabela 1). Apesar desses resultados, tanto a atividade redutora de $\mathrm{Fe}^{3+}$ quanto a atividade da MnP não apresentaram nenhuma correlação com o teor de TBARS produzidos in vivo.

Os teores de ácido oxálico extraído dos cultivos estão mostrados na Figura 2. De forma geral, os cultivos suplementados com óleo de soja e com ácido oxálico apresentaram os maiores teores de ácido oxálico total. Para o cultivo suplementado com ácido oxálico foi verificado o catabolismo deste pelo fungo, pois foram adicionados inicialmente $1,66 \mathrm{~g}$ de ácido oxálico $\mathrm{kg}^{-1}$. Além disso, esse quelante foi indisponibilizado por precipitação e esterificação, pois foi extraído significativamente com solução ácida e alcalina, respectivamente.

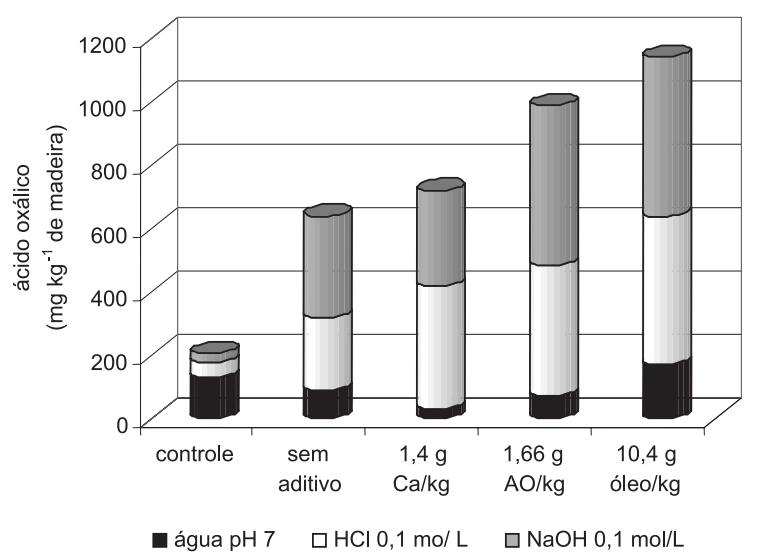

Figura 2. Produção de ácido oxálico $(A O)$ proveniente da biodegradação de P. taeda por C. subvermispora

\section{Determinação de atividade pró-oxidante dos caldos enzimáticos (in vitro)}

Na Figura 3 é mostrado um oxigrama referente à peroxidação do ácido linoleico pelo caldo enzimático proveniente do cultivo suplementado com ácido oxálico. Quando foram adicionados caldo enzimático, $\mathrm{Mn}^{2+}$ e emulsão de ácido linoleico em Tween 60 não foi observado consumo significativo de $\mathrm{O}_{2}$. Com a adição de $\mathrm{H}_{2} \mathrm{O}_{2}$, houve um pequeno aumento no teor de $\mathrm{O}_{2}$ dissolvido, seguido de uma queda progressiva, decorrente da peroxidação do ácido graxo. Para as outras amostras foi observado comportamento similar.

A Tabela 2 mostra que as atividades pró-oxidantes dos caldos (baseadas na taxa de consumo de $\mathrm{O}_{2}$ ) provenientes dos cultivos sem aditivo e daqueles adicionados de óleo de soja ou ácido oxálico foram estatisticamente similares. Por outro lado, não houve consumo de $\mathrm{O}_{2}$ pelo caldo proveniente do cultivo com cálcio, novamente devido à precipitação de oxalato de cálcio durante o ensaio. Ao se substituir o ácido oxálico por láctico, não houve precipitação, porém o consumo de $\mathrm{O}_{2}$ foi inexpressivo.

Quando foi excluída a emulsão de ácido linoleico em Tween 60, ainda houve um pequeno consumo de $\mathrm{O}_{2}$, que pode ser atribuído à oxidação de ácido oxálico por $\mathrm{Mn}^{3+},{ }^{19}$ ou à oxidação de compostos presentes no caldo enzimático, possivelmente fenóis que podem ser atacados por esse forte agente oxidante. Esse comportamento também foi observado por Kapich e colaboradores. ${ }^{10}$ Os valores mostrados na

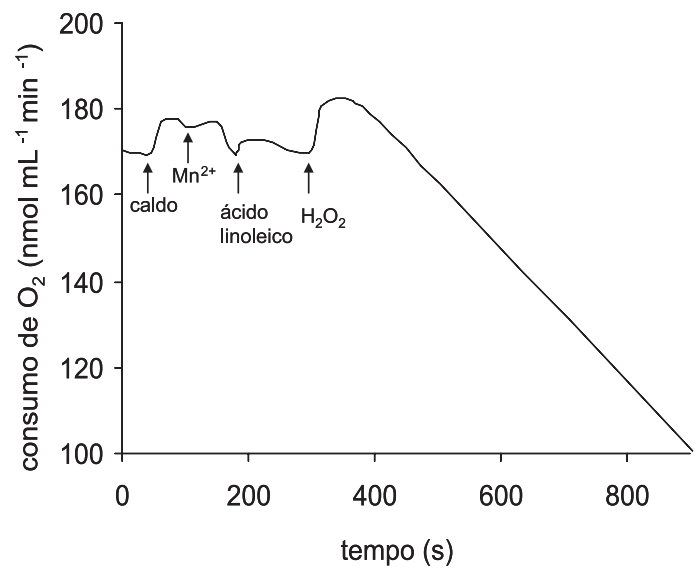

Figura 3. Oxigrama referente ao consumo de $\mathrm{O}_{2}$ causado pela peroxidação de ácido linoleico por $\mathrm{Mn}^{2+}, \mathrm{H}_{2} \mathrm{O}_{2}$ e caldo enzimático proveniente da biodegradação de P. taeda por C. subvermispora suplementado com 1,66 g de ácido oxálico $\mathrm{kg}^{-1}$ de madeira

Tabela 2. Atividade pró-oxidante baseada no consumo de $\mathrm{O}_{2}\left(\mathrm{UI} \mathrm{kg}^{-1}\right.$ de madeira) e formação de TBARS (nmols $\mathrm{mL}^{-1}$ de caldo) a partir da peroxidação de ácido linoleico in vitro pelos caldos enzimáticos provenientes da biodegradação de $P$. taeda por $C$. subvermispora

\begin{tabular}{lcc}
\hline Condição de cultivo & Atividade pró-oxidante & TBARS \\
\hline sem aditivo & $172 \pm 19$ (a)* & $6,5 \pm 1,0$ (a) \\
$1,4 \mathrm{~g} \mathrm{Ca}^{2+} \mathrm{kg}^{-1}$ & $* *$ & $1,6 \pm 0,7$ (b) \\
$1,66 \mathrm{~g}^{*}$ ácido oxálico kg-1 & $167 \pm 15$ (a) & $8,1 \pm 0,6$ (a) \\
$10,4 \mathrm{~g}_{\text {óleo de soja kg-1 }}^{-1}$ & $163 \pm 13$ (a) & $7,1 \pm 0,7$ (a) \\
\hline
\end{tabular}

*Em cada coluna, letras iguais indicam que os valores não diferem com $95 \%$ de confiança, letras diferentes indicam valores significativamente diferentes (teste de Dunnet). $* *$ Consumo de $\mathrm{O}_{2}$ inexpressivo.

Tabela 2 representam o consumo de $\mathrm{O}_{2}$ causado apenas pela peroxidação do ácido linoleico, descontando-se a interferência de outros compostos oxidáveis.

Para certificar que a atividade pró-oxidante era de origem enzimática, ao realizar o ensaio com caldo fervido não foi observado consumo de $\mathrm{O}_{2}$. Lacase de $C$. subvermispora também promove atividade pró-oxidante, mas dependente de $\mathrm{Mn}^{2+}$ e de um mediador fenólico, como o ácido $p$-hidroxi-benzoico. ${ }^{11}$ Como as atividades de lacase foram bem baixas, a atividade pró-oxidante global das culturas, neste trabalho, consistiu provavelmente na ação da $\mathrm{MnP}$ e na presença de compostos fenólicos provenientes da degradação de lignina e de extrativos fenólicos, os quais possuem efeito inibitório. ${ }^{21}$

A detecção de TBARS após a peroxidação in vitro de ácido linoleico seguiu a mesma tendência das taxas de consumo de $\mathrm{O}_{2}$ : similar entre os cultivos, com exceção daquele adicionado de cálcio, que foi inferior. Os valores de TBARS mostrados na Tabela 2 também foram descontados de reações realizadas na ausência de emulsão de ácido linoleico.

Os valores de atividade de MnP (com ácido oxálico como quelante) versus atividade pró-oxidante (taxa de consumo de $\mathrm{O}_{2}$ ) se correlacionaram positivamente (Figura 4). De acordo com o ponto próximo de zero (dados do cultivo com cálcio) fica claro que é necessária atividade significativa de MnP para promover atividade pró-oxidante. Cunha e colaboradores ${ }^{11}$ observaram correlação positiva entre $\mathrm{MnP}$ e taxa de consumo de $\mathrm{O}_{2}$ até $60 \mathrm{UI}$ de $\mathrm{MnP} \mathrm{kg}^{-1}$ de madeira, a partir de caldos enzimáticos provenientes da biodegradação de $E$. grandis por $C$. subvermispora. No presente trabalho, foi verificada correlação positiva para uma maior extensão, até $300 \mathrm{UI}$ de $\mathrm{MnP} \mathrm{kg}^{-1}$ de pinus. 
Por outro lado, Kapich e colaboradore ${ }^{10}$ não encontraram correlação entre produção de $\mathrm{MnP}$ e atividade pró-oxidante de culturas submersas de fungos de podridão branca. Dessa forma, a correlação positiva entre $\mathrm{MnP}$ e sua atividade pró-oxidante depende também do substrato utilizado na fermentação.

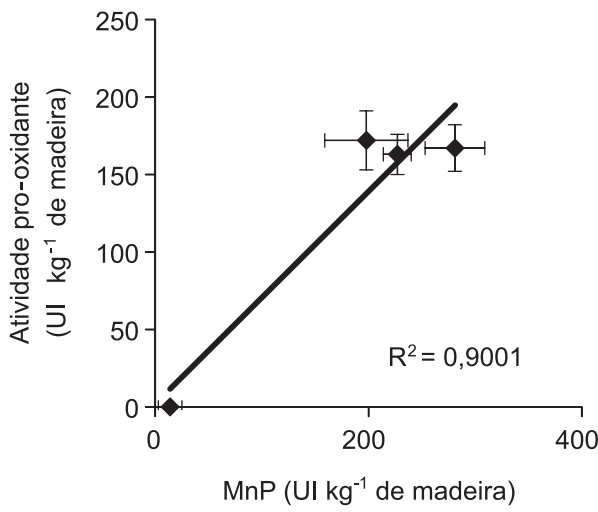

Figura 4. Correlação entre atividade pró-oxidante $\times$ MnP produzida por $C$. subvermispora durante a biodegradação de P. taeda

\section{CONCLUSÕES}

O uso de aditivos nos cultivos de C. subvermispora sobre madeira afetou a produção e/ou ação da MnP. De forma geral, os dados corroboram trabalhos da literatura que mostram uma dependência entre a atividade pró-oxidante observada nos cultivos e o nível de atividade da MnP. A importância de se avaliar a atividade pró-oxidante da MnP consiste no entendimento dos mecanismos de biodegradação da madeira, além do seu potencial em bioprocessos como o branqueamento de polpas celulósicas e a degradação de poluentes recalcitrantes.

\section{AGRADECIMENTOS}

À assistência técnica de J. S. Canilha, J. M. Silva e J. C. Tavares e às agências financiadoras $\mathrm{CNPq}, \mathrm{CAPES}$ e, principalmente, à FAPESP (processo 03/04465-6).

\section{REFERÊNCIAS}

1. Ferraz, A.; Guerra, A.; Mendonça, R.; Masarin, F.; Vicentim, M. P.; Aguiar, A.; Pavan, P. C.; Enzyme Microb. Technol. 2008, 43, 178.

2. Souza-Cruz, P. B.; Freer, J.; Siika-Aho, M.; Ferraz, A.; Enzyme Microb. Technol. 2004, 34, 228.

3. Aguiar, A.; Ferraz, A.; Int. Biodet. Biodegr. 2008, 61, 182.

4. Carvalho, W.; Ferraz, A.; Milagres, A. M. F.; Acta Sci. Technol. 2010, 32,347 .

5. Blanchette, R. A.; Krueger, E. W.; Haight, J. E.; Akhtar, M.; Akin, D. E.; J. Biotechnol. 1997, 53, 203.

6. Aguiar, A.; Ferraz, A.; Quim. Nova 2011, 34, 1729.

7. Jensen Jr., K.; Bao, W.; Kawai, S.; Srebotnik, E.; Hammel, K.; Appl. Environ. Microbiol. 1996, 62, 3679; Daina, S.; Orlandi, M.; Bestetti, G.; Wiik, C.; Elegir, G.; Enzyme Microb. Technol. 2002, 30, 499.

8. Moen, M. A.; Hammel, K. E.; Appl. Environ. Microbiol. 1994, 60, 1956; Bogan, B. W.; Lamar, R. T.; Hammel, K. E.; Appl. Environ. Microbiol. 1996, 62, 1788.

9. Bermek, H.; Li, K.; Eriksson, K. E. L.; Bioresour. Technol. 2002, 85, 249; Xu, H.; Scott, C. M.; Jiang, F.; Kelly, C.; Holzforchung 2010, 64, 137.

10. Kapich, A. N.; Prior, B. A.; Lundell, T.; Hatakka, A.; J. Microbiol. Methods 2005, 51, 261.

11. Cunha, G. G. S.; Masarin, F.; Norambuena, M.; Freer, J.; Ferraz, A.; Enzyme Microb. Technol. 2010, 46, 262.

12. Aguiar, A.; Ferraz, A.; $11^{\text {th }}$ International Chemical and Biological Engineering Conference, Lisboa, Portugal, 2011.

13. Aguiar, A.; Mendonça, R.; Rodriguez, J.; Ferraz, A.; Int. Biodet. Biodegr. 2010, 64, 588.

14. Elissetche, J.; Ferraz, A.; Freer, J.; Mendonça, R.; Rodríguez, J.;. FEMS Microbiol. Lett. 2006, 260, 112.

15. Wood, T. M.; Bhat, K. M.; Methods Enzymol. 1988, 160, 87.

16. Bailey, M. J.; Biely, P.; Poutanen, K.; J. Biotechnol. 1992, 23, 257.

17. Buege, J. A.; Aust, S. D.; Methods Enzymol. 1978, 52, 302.

18. Ferraz, A.; Baeza, J.; Rodríguez, J.; Freer, J.; Bioresour. Technol. 2000, 74, 201.

19. Urzúa, U.; Kersten, P. J.; Vicuña, R.; Appl. Environ. Microbiol. 1998, 64, 68.

20. Horta, M. A.; Masarin, F.; Rodríguez, J.; Ferraz, A.; Int. Biodet. Biodegr. 2011, 65, 164 .

21. Kapich, A.; Galkin, S.; Hatakka, A.; Biocatal. Biotransform. 2007, 25, 350 . 